\title{
Systemic nodular panniculitis with cardiac involvement
}

\author{
P. J. WILKINSON, R. R. M. HARMAN, AND C. R. TRIBE \\ From the Departments of Pathology and Dermatology, Southmead Hospital, Bristol
}

SYNOPSIS A case of systemic nodular panniculitis is described in which the myocardium was found at necropsy to be extensively involved with focal interstitial carditis, identical histologically with nodules of panniculitis biopsied from the skin. This degree of myocardial involvement, which was not apparent during life and was not confined to pericardial or myocardial adipose tissue, has not previously been reported. The literature relating to nodular panniculitis is briefly reviewed and the concept of Weber-Christian disease critically re-appraised.

Nodular panniculitis involving the subcutaneous tissues of the trunk and extremities was first described by Pfeifer (1892). Gilchrist and Ketron (1916) reported a similar case in which fat had been ingested by macrophages. A third case was described by Weber (1925) who named the condition 'relapsing, non-suppurative nodular panniculitis'. Christian (1928) presented a fourth case and suggested that the term 'febrile' be added to the title of the disease. The eponym 'Weber-Christian disease' was introduced by Brill (1936) and so a clinical syndrome was born under whose name more than one hundred cases have been documented in the literature. Numerous features have since been associated with this syndrome, and Milner and Mitchinson (1965) described a case with widespread systemic involvement, coining the term 'systemic Weber-Christian disease'. In this, as in other cases which they reviewed, peritoneal and pericardial adipose tissues were shown at necropsy to be involved, sometimes to a considerable extent.

Weber-Christian disease, as classically described, is a relapsing condition with a predilection for women in the second to fourth decade of life. It is characterized by crops of painful, tender, subcutaneous nodules (of diameter 1 to $12 \mathrm{~cm}$ ), found particularly on the thighs and buttocks. Systemic symptoms such as fever, nausea, vomiting, myalgia and arthralgia usually accompany each outbreak and may persist for a few weeks or months. Moderate leucopaenia, anaemia, a high erythrocyte sedimentation rate, a haemorrhagic diathesis and visceromegaly may all be associated. If the nodules are biopReceived for publication 15 July 1974. sied in the acute phase, a picture of inflammation and necrosis of the subcutaneous adipose tissue is seen, ie, a nodular, subcutaneous panniculitis.

The unique feature of the present case is the severity of the interstitial carditis, in which areas of chronic inflammatory granulomatous infiltration ex tended deeply into the myocardium. In many areas, this myocarditis was identical with panniculitic lesions in the subcutaneous and pericardial adipose tissues.

\section{Case Summary ${ }^{1}$}

A female patient at the age of 63 developed chronic left leg ulcers which required skin grafting. The grafts ulcerated six months later and at approximately the same time painful, purple, nodular subcutaneous lesions ( 1 to $2 \mathrm{~cm}$ diameter) appeared on both thighs, legs, and calves. Biopsy of these (figs 1 to 3) showed foci of subcutaneous fat cell necrosis surrounded by a polymorphonuclear and histiocytic inflammatory cell exudate, the appearances of nodular, non-suppurative panniculitis.

These nodules recurred in crops over a period of about six months, during which time a second skin graft failed because of infection.

A painful nasal swelling developed in the following year, with a collapse of the nasal cartilage and a large septal perforation. Biopsy showed granulation tissue with an intense mixed acute and chronic inflammatory cell infiltration rich in plasma cells. This was thought to be consistent with a diagnosis of midline granuloma, probably of the histiocytic ${ }^{1}$ Further details available from authors on request. 


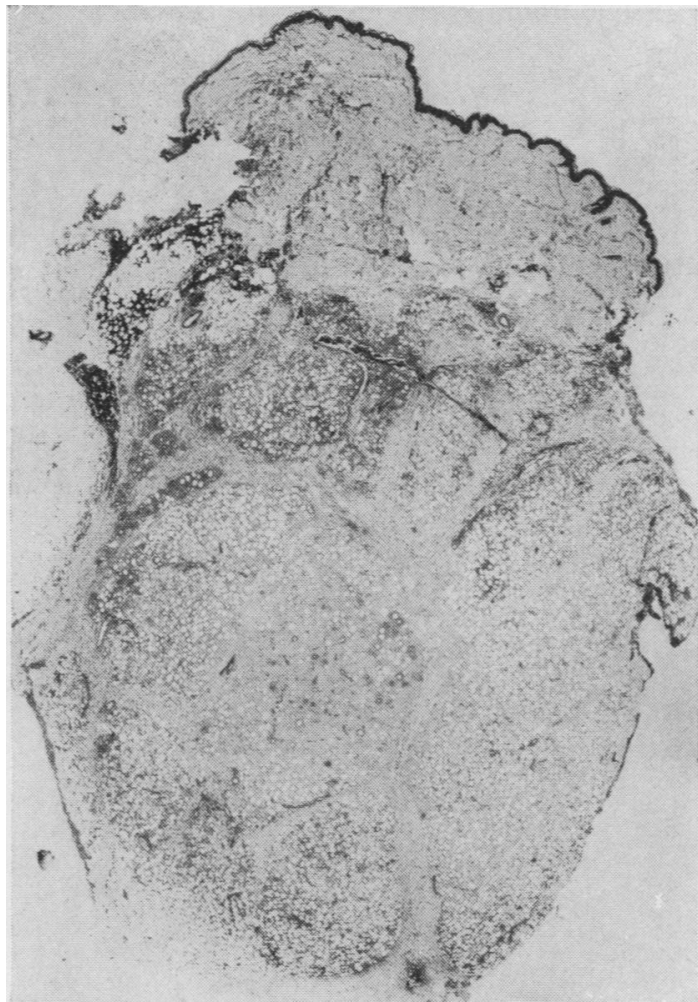

Fig 1

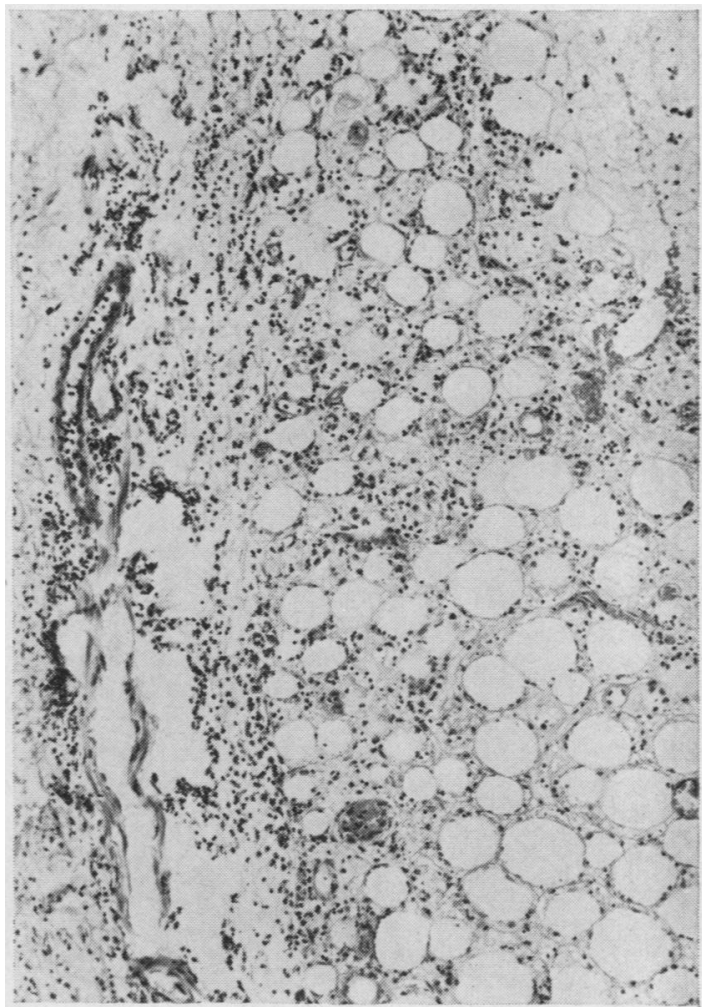

Fig 2

Fig 1 Skin nodule from left leg (biopsy S70/4490; H.\& E. $\times 13$ ). There is a discrete nodule in the subcutaneous tissue showing panniculitic infiltration of the adipose tissue, in the centre of which is an area of necrosis.

Fig 2 Edge of skin nodule $(S 70 / 4490 ; H . \&$ E. $\times 140)$ showing chronic panniculitis with histiocytes and small round cells.

Stewart type (Stewart, 1933), and appeared to be unrelated to the panniculitis.

Numerous investigations during several periods in hospital revealed remarkably few abnormalities. The ESR was $78 \mathrm{~mm} / \mathrm{hr}$ initially but was normal in the presence of the skin nodules, as were the WBC and differential counts (apart from an occasional mild eosinophilia).

The latex slide rheumatoid arthritis test, antinuclear factor, and Wassermann reactions were negative. LE cells were not found. Blood pressure and ECGs remained normal, and so was a renal biopsy, performed to exclude arteritis or collagen disease. Treatment with prednisone was then instituted.

After being moderately well for a further six months, the patient was admitted as an emergency with symptoms and signs of acute liver failure. She was jaundiced and liver function tests were highly suggestive of viral hepatitis. She died four days later, two years after the original biopsy diagnosis of cutaneous nodular panniculitis.

\section{Pathological Summary}

Postmortem examination was limited on account of the risk to staff. The nasal perforations were as described in life, and scars were present on the legs at the sites of former ulcers, though no skin nodules were found. The heart showed a mild fibrinous pericarditis but in other respects was grossly normal. The liver was small and pale.

Histological examination of the liver showed changes of a fulminating hepatitis. Other organs were non-diagnostic except for the heart where small areas of panniculitis were found in the pericardial adipose tissue (fig 4) and many very similar small and medium-sized granulomatous foci composed of histiocytes, lymphocytes, and eosinophils with central necrosis in the larger lesions were seen within the myocardium (figs 5 and 6). Where they involved fat, the granulomata were striking in their similarity to the original subcutaneous nodules (figs 1 to 3 ) and similar lesions were seen in mediastinal adipose 


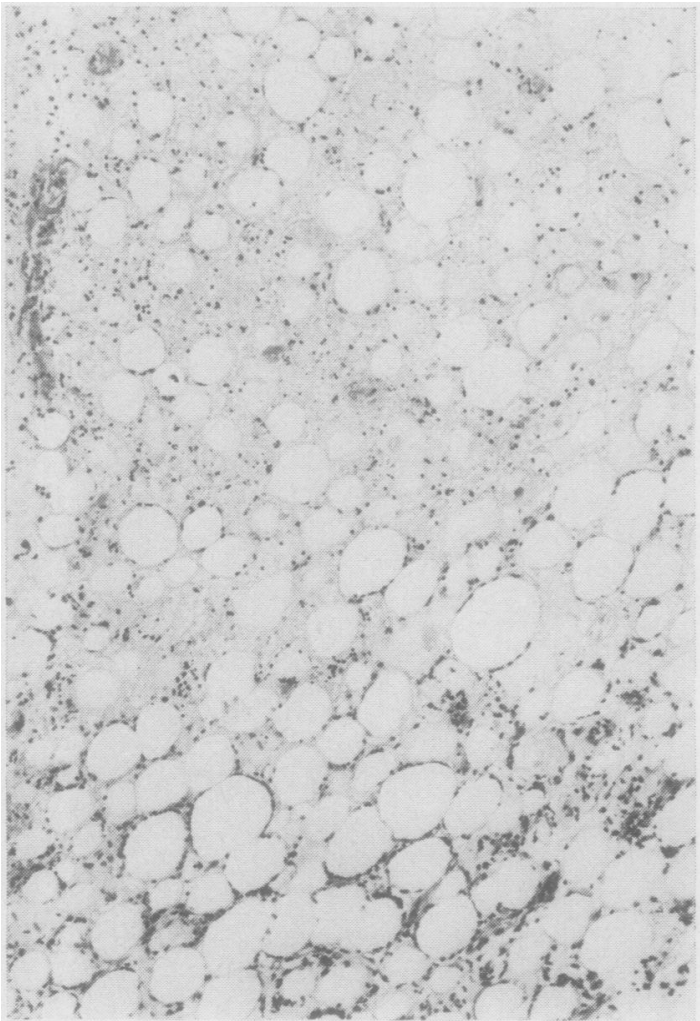

Fig 3

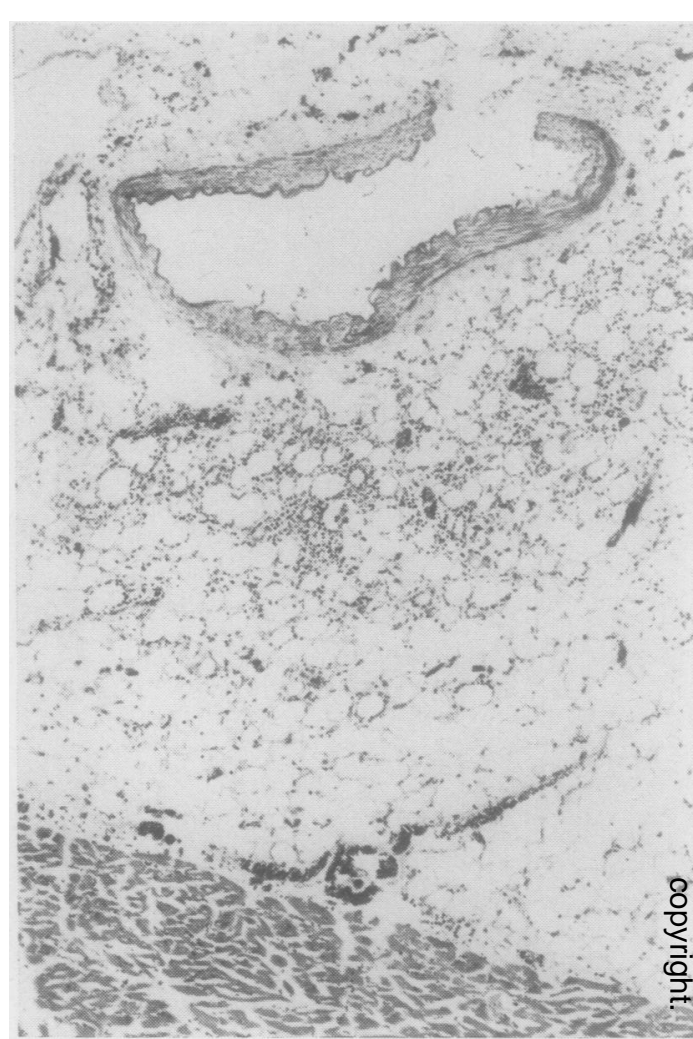

Fig 4

Fig 3 Centre of skin nodule $(S 70 / 4490 ; H . \&$ E. $\times 140)$ showing the fat necrosis.

Fig 4 Pericardium (necropsy 10/72; H.\& E. $\times 70$ ) showing a focus of chronic panniculitis in the pericardial fat similar in type to the skin nodule biopsy illustrated in figures 1 to 3 .

tissue but in no other organs. Many of the peculiar myocardial granulomata were, however, dissociated from fatty tissue (fig 6).

\section{Discussion}

There have been many communications in recent years describing the numerous and varied associations of this syndrome and speculating about its aetiology.

Beerman (1953) reviewed the Weber-Christian syndrome and suggested an aetiological classification. Hallahan and Klein (1951) and Steinberg (1953) also reported cases and reviewed all knowledge to date. Many associations have since been described including mechanical trauma (Sarkany and Macmillan, 1970), cold trauma (Epstein and Oren, 1970), factitial injury (Ackerman, Mosher, and Schwamm, 1966), intraadipose injection of irritant drugs (Rinaldi, 1958), pancreatic disease (Emmerson, 1966; Graciansky, 1967; Robertson and Eeles, 1970), and steroid therapy (Spagnuolo and Taranta, 1951).
Infectious and inflammatory associations include mycobacterial infection (Cantwell, Craggs, Swatek, and Wilson, 1966), toxoplasmosis (Østergaard, 1970), sarcoid (Perry and Winkelmann, 1964), aortitis (Farkas, Kálló, Hódy, and Miklós, 1960), sterile chronic inflammation of the intramedullary fat of the tibia (Pinals, 1970), and rheumatic fever (Brudno, 1950). Some authors have implicated immunological mechanisms, citing associations with $\frac{T}{0}$ lupus erythematosus with a positive LE cell test (Macoul, 1967), lupus erythematosus profundus $N$ (Tuffanelli, 1971), or circulating leucoagglutinins $N$ (Rosenstock, 1968). Associated haematological $\mathcal{N}$ diseases have included pancytopenia (Wyatt, 1969; $\omega$ Sanford, Eubank, and Stenn, 1952) and myelofibrosis with leuco-erythroblastic anaemia (Duffy, 을 1963). A number of cases of peritoneal or mesenteric $\stackrel{\mathbb{D}}{\mathscr{N}}$ panniculitis have been considered idiopathic (Crane, Aguilar, and Grimes, 1955; Sattler and Greenberg, 1956; Tedeschi and Botta, 1962; Grossman, Kaplan, Preuss, and Herrington, 1963; Soergel and Hensley 1966). 


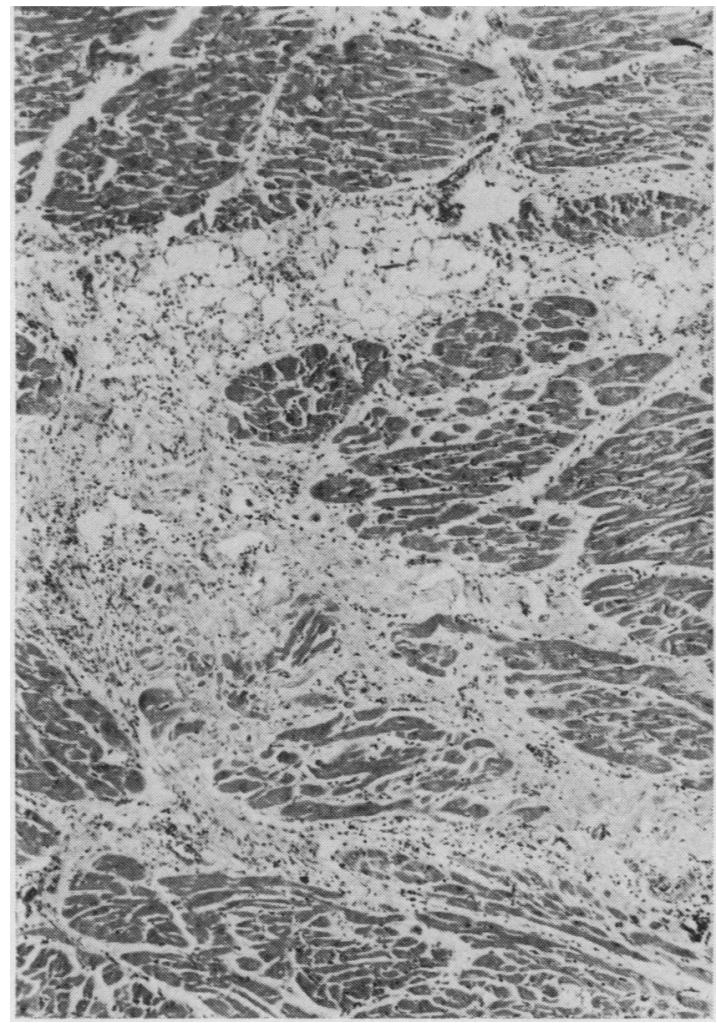

Fig 5

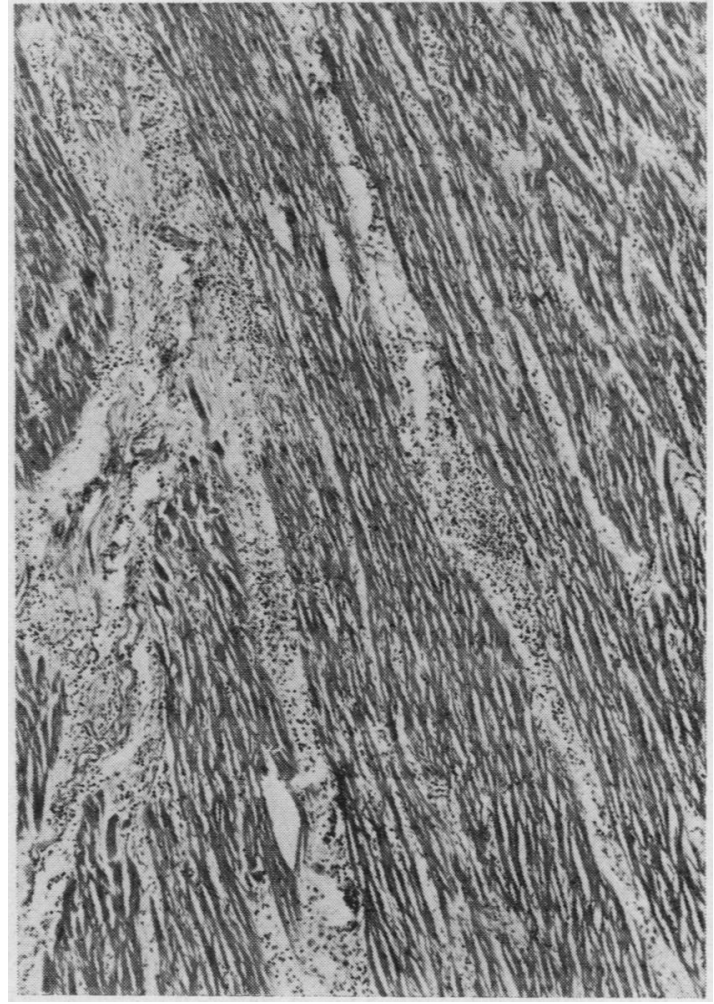

Fig 6

Fig 5 Myocardium (necropsy 10/72; H.\& E. $\times 75$ ) showing a granuloma consisting of histiocytes, lymphocytes, eosinophils, and polymorphs with some interstitial panniculitis.

Fig 6 Myocardium (necropsy 10/72; H. \& E. $\times 70$ ) showing focal granulomatous infiltration between non-necrotic myocardium and not associated with adipose tissue.

Such has been the diversity of the factors associated with Weber-Christian disease that Macdonald and Feiwel (1968) considered it very unlikely that this condition exists as a nosological entity. They proposed that the lesions be regarded simply as 'nodular panniculitis', as one of the symptoms or manifestations of a variety of causes and conditions. In a later paper, Macdonald (1970) reviewed the localized disorders of fatty tissues, namely, tumours, eg, lipoma, atrophic conditions, eg, lipodystrophy, and inflammatory states, eg, panniculitis. He divided nodular panniculitis into four broad groups of conditions according to the associated features which may or may not have been causative. These groups were (1) physical or chemical agents, (2) infective agents, (3) immunological reactions, and (4) idiopathic.

In the case described in this paper, no physical or chemical agents can be implicated from the history. The first crop of nodules, from which the biopsy was taken, erupted after a period of chronic cutaneous ulceration on the left leg, during which time a skin graft to the deepest ulcer failed to take.

An immunological disorder was repeatedly sought during her illness. However, with an ESR never higher than $18 \mathrm{~mm} / \mathrm{hr}$ following the development of subcutaneous panniculitis, repeatedly negative tests for rheumatoid factor, LE cells, and antinuclear factor, and also normal vascular histology of a renal biopsy, this was considered unlikely. A mild eosinophilia during life taken in conjunction with the eosinophilic infiltration in the spleen, liver, and adrenals, and the peculiar fibrinoid reaction in the splenic capsule do suggest some possible immunological disturbance of the connective tissues. The case would otherwise appear to belong to the idiopathic group.

The oro-nasal fistula was histologically a nonspecific granuloma and distinct from the panniculitis seen in the skin during life and in the pericardium and myocardium at necropsy. It behaved clinically as a histiocytic midline granuloma of the Stewart 
type (Stewart, 1933). This did not appear to be connected with the systemic nodular panniculitis.

Milner and Mitchinson (1965) suggested that the name 'systemic Weber-Christian disease' be applied when the lesions occur in adipose tissue other than the panniculus, and that 'Weber-Christian panniculitis' be used when the lesions are confined to the subcutaneous adipose tissue. The cases which they described showed widespread involvement of adipose tissue around the retroperitoneal viscera, the paraaortic lymph nodes, and some scattered lesions in the lung. The necrosis and inflammation extended into some of the organs adjacent to areas of panniculitis. They reviewed 11 earlier cases with systemic involvement which were examined at necropsy, of which six had pericardial involvement and two myocardial; however, in one of these (Steinberg 1953), the myocardium showed patchy fibrosis only, with arteriosclerosis of the intramural coronary arteries; no inflammatory infiltration was seen. In the other (Hutt and Pinniger, 1956), there was patchy cellular infiltration of the myocardium together; degeneration of myocardial fibres, and occasional clusters of cells in the perivascular connective tissue in a manner reminiscent of Aschoff nodes. This infiltrate was much less extensive than that described in our case.

The patient reported in this paper undoubtedly had systemic nodular panniculitis. The apparent absence of cardiac symptoms during life and the normal ECG in the presence of such widespread myocardial involvement is remarkable. This emphasizes the need for an awareness of possible systemic involvement of vital organs in patients with nodular panniculitis.

\section{References}

Ackerman, A. B., Mosher, D. T., and Schwamm, H. A. (1966). Factitial Weber-Christian syndrome. J. Amer. med. Ass., 198, 731-736.

Beerman, H. (1953). Weber-Christian syndrome. Amer. J. med. Sci., 225, 446-462.

Brill, I. C. (1936). Relapsing febrile, nodular, non-suppurative panniculitis. (Weber-Christian disease). In Medical Papers Dedicated to H. A. Christian, pp. 694-704, Waverly Press, Baltimore.

Brudno, J. C. (1950). Chronic relapsing febrile nodular nonsuppurative panniculitis (Weber-Christian disease): relation to rheumatic fever and allied diseases. New Engl. J. Med., 243, 513-517.

Cantwell, A. R. Jr., Craggs, E., Swatek, F., and Wilson, J. W. (1966). Unusual acid-fast bacteria in panniculitis. Arch. Derm., 94, 161-167.

Christian, H. A. (1928). Relapsing febrile nodular nonsuppurative panniculitis. Arch. intern. Med., 42, 338-351.

Crane, J. T., Aguilar, M. J., and Grimes, O. F. (1955). Isolated lipodystrophy: a form of mesenteric tumor. Amer. J. Surg., 90, 169179.

Duffy, J. P. (1963). Weber-Christian disease with myelofibrosis and destructive bone lesions. J. Irish. med. Ass., 52, 62-65.

Emmerson, R. W. (1966). Liquefying nodular panniculitis and diabetes. Proc. roy. Soc. Med., 59, 252-253.

Epstein, E. H., Jr., and Oren, M. E. (1970). Popsicle panniculitis. New Engl. J. Med., 282, 966-967.

Farkas, G., Kálló, Ä., Hódy, L., and Miklós, G. (1960). Úber einen Fall: von Weber-Christianscher Pannikulitis mit gleichzeitigem Aortenbogen Syndrom. Z. Kreisl. -Forsch., 49, 815-821.

Gilchrist, T. C., and Ketron, L. W. (1916). A unique case of atrophy of the fatty layer of the skin, preceded by the ingestion of the fat by large phagocytic cells-macrophages. Johns Hopk. Hosp. Bull., 27, 291-294.

de Graciansky, P. (1967). Weber-Christian syndrome of pancreatic origin. Brit. J. Derm., 79, 278-283.

Grossman, L. A., Kaplan, H. J., Preuss, H. J., and Herrington, J. L., Jr. (1963). Mesenteric panniculitis. J. Amer. med. Ass., 183, 318-323.

Hallahan, J. D., and Klein, T. (1951). Relapsing febrile nodular nonsuppurative panniculitis (Weber-Christian disease): review of literature and report of case. Ann. intern. Med., 34, 1179-1201.

Hutt, M. S. R., and Pinniger, J. L. (1956). Adrenal failure due to bilateral suprarenal infarction associated with systemic nodular panniculitis and endarteritis. J. clin. Path., 9, 316-322.

MacDonald, A., and Feiwel, M. (1968). A review of the concept of Weber-Christian panniculitis with a report of five cases. Brit. J. Derm., 80, 355-361.

MacDonald, A. (1970). Inflammatory diseases of the subcutaneous fat Geriatrics, 25, (11), 156-174

Macoul, K. L. (1967). Panniculitis, vasculitis and a positive lupus erythematosus cell test. J. Amer. med. Ass., 199, 428-430.

Milner, R. D. G., and Mitchinson, M. J. (1965). Systemic WeberChristian disease. J. clin. Path., 18, 150-156.

Østergaard, P. A. (1970). Weber-Christian disease. Toxoplasmosis as a possible aetiological factor in panniculitis of the WeberChristian type. Dan. med. Bull., 17, 158-160.

Perry, H. O, and Winkelmann, R, K. (1964), Subacute nodula migratory panniculitis. Arch. Derm., 89, 170-179.

Pinals, R. S. (1970). Nodular panniculitis associated with an inflar matory bone lesion. Arch. Derm. 101, 359-363.

Pfeifer, V. (1892). Uber einen Fall von herdweiser Atrophie des sub cutanen Fettgewebes. Dtsch. Arch. klin. Med., 50, 438-449.

Rinaldi, V. G. (1958). Steatonecrosi cistiche multiple e simultanee da penicillina ritardo. Rif. med., 72, 207-209.

Robertson, J. C., and Eeles, G. H. (1970). Syndrome associated with pancreatic acinar cell carcinoma. Brit. med. J., 2, 708-709.

Rosenstock, H. A. (1968). Weber-Christian disease: report of a case documenting the presence of leukoagglutinins. J. Amer. med. Ass., 203, 890-891.

Sanford, H. N., Eubank, D. F., and Stenn, F. (1952). Chronic panniculitis with leucopenia (Weber-Christian syndrome). Amer. J. Dis. Child, 83, 156-163.

Sarkany, I., and Macmillan, A. L. (1970). Recurrent non-scarring pressure panniculitis. Proc. roy. Soc. Med., 62, 1279-1280.

Sattler, M. E., and Greenberg, A. I. (1956). Bowel obstruction, unusual manifestation of Weber-Christian disease. Wisc. med. J., 55, 1219-1222.

Soergel, K. H., and Hensley, G. T. (1966). Fatal mesenteric panniculitis. Gastroenterology, 51, 529-536.

Spagnuolo, M., and Taranta, A. (1961). Post-steroid panniculitis. Ann. intern. Med., 54, 1181-1190.

Steinberg, B. (1953). Systemic nodular panniculitis. Amer. J. Path., 29, 1059-1081.

Stewart, J. P. (1933). Progressive lethal granulomatous ulceration of the nose. J. Laryng., 48, 657-701.

Tedeschi, C. G., and Botta, G. C. (1962). Retractile mesenteritis. New $\sigma$ Engl. J. Med., 266, 1035-1040.

Tuffanelli, D. L. (1971). Lupus erythematosus panniculitis(Profundus): clinical and immunologic studies. Arch. Derm., 103, 231-242.

Weber, F. P. (1925). A case of relapsing non-suppurative nodular panniculitis showing phagocytosis of subcutaneous fat cells by macrophages. Brit. J. Derm., 37, 301-311.

Wyatt, E. H. (1969). Panniculitis and pancytopenia. Brit. J. clin. Pract., 23, 473-476. 